\title{
Life Events, Depression and Hypothalamic-Pituitary-Adrenal Axis Function
}

\author{
R. J. DOLAN, S. P. CALLOWAY, P. FONAGY, F. V. A. DE SOUZA and A. WAKELING
}

The relationship between antecedent life events, clinical profile, and hypothalamicpituitary-adrenal function was examined in 72 depressed patients. Antecedent life events were associated with first episodes of depression and with greater severity of illness, but their presence did not distinguish between patients diagnosed as endogenous or neurotic, and status on the dexamethasone suppression test was not associated with a greater or lesser likelihood of antecedent events. However, urinary free cortisol levels were higher in those patients with life events and difficulties.

An increased rate of antecedent life events is reported in depressed subjects in both community and hospital-based studies (Lloyd, 1980), though the nature of the association is disputed. Brown \& Harris (1978) have argued a causative role for life events in the aetiology of depression, but this viewpoint has been opposed chiefly on the grounds that 'cases' in their community studies are not representative of 'cases' seen by psychiatrists in hospital settings. It has been maintained that life events are more likely to give rise to distress rather than depressive illness and that explanations based on the former cannot be extrapolated to the latter (Bebbington et al, 1981). Distress is adequately explained in terms of adversity, whilst depressive illness requires the invocation of disease theories.

The above argument typifies a major difficulty in psychiatric research-lack of precision, of consensus in the definition of 'caseness', and of an independent validation of diagnosis. However, the dexamethasone suppression test (DST) has been widely used as a diagnostic tool with a high specificity for 'endogenous' depression (Carroll, 1982; Holden, 1983). Some of these issues have been examined, using data collected in a large-scale study of neuroendocrine abnormalities in depression (Calloway et al, 1984). This present paper reports on: the relationship of life events to the onset and clinical characteristics of depression in the patients under study; and the relationship of life events to neuroendocrine change, including patient status on the DST.

\section{Method}

Subjects

Patients were selected on the basis of Research Diagnostic Criteria (RDC) for primary depression (Spitzer et al, 1978). All were free of physical illness on the basis of a physical examination, routine blood tests, and EEG. They came from a psychiatric hospital, a district general hospital, and general practice.

\section{Diagnosis}

Clinical data was elicited using the Hamilton Rating Scale (HAMD) (Hamilton, 1960), the Present State Examination (PSE) (Wing et al, 1974), and the Newcastle Diagnostic Index (NDI) (Carney et al, 1965). The HAMD was used as a global measure of severity, while the PSE and NDI were used to classify the patients into sub-classes of endogenous and neurotic.

Patients with affective disorder are allocated by the CATEGO programme to three classes-D, $R$ and $N$. Whilst $D$ and $N$ fall respectively within the conventional ICD classifications of 'Psychotic depression' and 'depressive neurosis', $R$ does not readily conform to a particular ICD classification. However, given that it is characterised by such symptoms as retardation and pathological guilt, it was taken to be a close enough approximation of the symptom pattern of endogenous depression to be used as synonomous with this classification. This strategy for allocation of patients to diagnostic categories is similar to that of Bebbington (1981), and classes $R$ and $D$ were thus taken to be synonomous with endogenous depression. In addition, the PSE was used to assess severity of depression, using total scores, and to obtain syndrome scores derived from the summed scores of symptom groups.

Using the NDI, patients scoring 6 or greater were taken to be 'endogenous', whilst those with less than 6 were taken to be 'neurotic' (Carney et al, 1965).

\section{Social assessment}

The instrument used was the Bedford College Life Events and Difficulties Schedule (Brown \& Harris, 1978) and was administered by two trained raters ( $R$ D and S P C). This is a wide-ranging, semi-structured interview, which elicits two types of information-life events, which are discrete stressors, and difficulties, i.e., ongoing stressors in the patient's life.

Events and difficulties were rated as present if they met pre-defined inclusion criteria. Ratings were also made of the independence, focus, and long-term contextual threat 
of both events and difficulties. On the basis of these measures, only severe events and major difficulties (Brown \& Harris, 1978) were included in the analysis of clinical data. In addition, a precise dating of the event was made, with particular emphasis on its temporal relationship to the onset of illness.

Events were included only if they occurred in the six months prior to onset of depression; this was based on the fact that previous studies have shown that events of casual importance usually occur within six months of onset. In examining the relationship of 24-hour urinary cortisols to difficulties, we included the latter if they had been present for at least one year before onset, fulfilling Brown \& Harris' criteria for 'marked difficulties'. This decision was made at the pre-analytical stage of the study, in order to obtain a reasonable sample size of patients with difficulties.

Finally, when examining the association between 24-hour urinary free cortisol levels and life events, two separate analyses were carried out-firstly including only events occurring in the six months prior to onset of illness, and then a separate analysis including events in the six months prior to investigation. This was based on the fact that many of the patients experienced life events after the onset of their disorder. If it is hypothesised that hypothalamic-pituitary-adrenal function is influenced by stress, then there is no rationale for excluding such events.

\section{Neuroendocrine assessment}

Neuroendocrine status was assessed for each patient in the following manner. After a three-day acclimatisation period, a 24-hour urine collection was taken from $11 \mathrm{pm}$ on day 1 to $11 \mathrm{pm}$ on day 2 . A second 24-hour urine collection was started on day 2 , after the oral administration of $1 \mathrm{mgm}$ of dexamethasone at $11 \mathrm{pm}$. On day 2, a $4 \mathrm{pm}$ blood sample was taken for plasma cortisol. The two 24-hour urine collections were assessed for pre- and postdexamethasone urinary free cortisol (UFC) respectively.

Cortisols in plasma and urine were measured in duplicate, using a double antibody radio-immuno-assay method (Amerlex Cortisols RA kit). The coefficient of variation for repeated assays was $4.4 \%$. A cut-off point of 5 micrograms/dl was taken to define non-suppressors on $4 \mathrm{pm}$ plasma cortisols (Carroll, 1982).

\section{Siatistics}

Results were analysed utilising the chi-square, analysis of variance (Anova), and Brown-Forsythe tests (Brown \& Forsythe, 1974). The particular statistics used are indicated in the relevant Tables. Comparisons between groups for urinary free cortisol levels were performed using the log of the UFC (Carroll el al, 1976).

\section{Results}

\section{Demographic and clinical features}

Seventy-two patients met the entry criteria for the study: $28(39 \%)$ were in-patients; $43(60 \%)$ were female; six of the out-patients and two of the in-patients were referred from general practice for the study. The mean age of the sample was 41.6 years; $21(29 \%)$ of the patients were experiencing their first episode of depression. The RDC diagnoses of the patients were major depressive disorder (54), probable major depressive disorder (9) and minor depressive disorder (9). Using the PSE index of definition (Wing et al, 1974), 70 of the 72 patients met the criteria of caseness. The PSE classes of the patients were depressive psychosis (6), retarded depression (33), neurotic depression (29), anxiety neurosis (2), paranoia (1) and obsessional neurosis (1). The mean HAMD score of the sample was 20.4 $( \pm 7.1)$. Using the NDI, half of the patients were classified as endogenous and half as neurotic.

\section{Overall incidence of life events and difficulties}

In $39 \%$ of the patients, there was a severe life event before onset of their illness, and in $21 \%$ of the sample there was a major difficulty before onset $(26 \%$ had a marked difficulty, ie present for over a year before onset). Fiftyfour per cent of patients had either a severe life event or major difficulty before onset.

\section{Clinical profile and life events/difficulties}

Severity Table I shows a comparison of overall severity of depression, as measured by the HAMD and total PSE score, in patients with and without antecedent life events. Patients with severe life events had a significantly greater mean HAMD score $(P<0.05)$ and a greater total PSE score $(P<0.01)$. There was no association between severity on these two scales and the presence or absence of major

TABLE I

Mean Hamilton and PSE scores for patients with and without severe life events

\begin{tabular}{lccl}
\hline & $\begin{array}{c}\text { Severe events } \\
n=28\end{array}$ & $\begin{array}{c}\text { No events } \\
n=44\end{array}$ & ANOVA \\
\hline Hamilion Score & $22.7 \pm 7.0$ & $18.9 \pm 6.8$ & $\mathrm{~F}=5.2, \mathrm{df} 72,1, \mathrm{P}<0.05$ \\
PSE Score & $30.4 \pm 11.3$ & $24.1 \pm 8.7$ & $\mathrm{~F}=6.9, \mathrm{df} 72,1, \mathrm{P}<0.01$ \\
SD & $3.8 \pm 2.1$ & $3.8 \pm 2.0$ & $\mathrm{~N} . \mathrm{S}$. \\
OD & $3.5 \pm 1.6$ & $2.2 \pm 1.8$ & $\mathrm{~F}=9.12, \mathrm{df} 72,1, \mathrm{P}<0.005$ \\
ED & $1.3 \pm 1.6$ & $1.0 \pm 1.0$ & $\mathrm{~N} . \mathrm{S}$. \\
SL & $0.9 \pm 1.7$ & $1.2 \pm 1.7$ & N.S. \\
GA & $1.7 \pm 1.4$ & $1.5 \pm 1.4$ & N.S. \\
WO & $5.0 \pm 1.7$ & $3.7 \pm 1.9$ & $\mathrm{~F}=9.25, \mathrm{df} 72,1, \mathrm{P}<0.005$ \\
TE & $2.8 \pm 1.3$ & $2.0 \pm 1.5$ & $\mathrm{~F}=4.6, \mathrm{df} 72,1, \mathrm{P}<0.05$ \\
\hline
\end{tabular}


difficulties. To determine whether this difference in overall severity in patients with life events was accounted for by greater overall scores for particular symptom constellations, the PSE syndrome scores of patients with life events were contrasted with those without.

Patients with severe life events had significantly greater mean scores for the syndrome OD $(P<0.005)$, made up of morning depression, loss of appetite, early waking, loss of libido, and premenstrual exacerbation. They had also significantly greater mean scores for the syndromes WO $(P<0.05)$, made up of worrying, tiredness, nervous tension, neglect through brooding, and delayed sleep; and TE $(P<0.005)$ made up of tension pains, muscular tension and restlessness. There were no differences between the groups for the syndromes GA (general anxiety), ED, which includes symptoms of guilt, or SL, the PSE measure of retardation.

Endogenous/neurotic There were no significant differences in the incidence of severe life events in patients falling within class $N$, when compared to $R$ and $D ; 50 \%$ of the former had life events, compared to $32 \%$ of the latter. Furthermore, when we considered major difficulties as well as life events as possible precipitants, no differences emerged.

Using the NDI to allocate patients to the diagnostic groups of endogenous or neurotic, there were no significant differences in the incidence of antecedent life events, comparing the two groups. Similarly, major difficulties and severe life events combined were not associated with either endogenous or neurotic depression, using the above diagnostic criteria.

Life events A comparison of patients who were experiencing their first episode of depression with those who had had one or more previous episodes revealed a significant difference: $62 \%$ of the former had a life event, compared to $29 \%$ of the latter $(\mathrm{P}<0.05)$. There were no differences in the incidence of major difficulties, age, or overall severity of illness, as measured by the HAMD or total PSE score between patients with a first onset of depression, compared to those with a previous history.

There were, however, differences between these groups in symptom profiles, which were revealed by comparing their overall scores on the PSE syndromes. Patients with a first onset of depression had significantly greater mean scores for the PSE syndrome OD $(P<0.01)$, and for WO $(P<0.05)$; those with a previous history of depression had a significantly greater mean score for $\mathrm{ED}(\mathrm{P}<0.05)$, made up of self-deprecation, guilty ideas of reference, guilt, dulled perception, and loss of affect.

Forty-two per cent of the sample had a family history of depression, established on the basis of patients' own reports, examination of case notes if relevant, and an interview with a first-degree relative. The presence of a family history was not associated with a greater or lesser likelihood of an antecedent life event or difficulty.

Neuroendocrine status and life events/difficulties

Dexamethasone suppression test (DST) Suppressor/ non-suppressor status on the DST was not associated with a greater or lesser likelihood of antecedent life events or difficulties. Of the overall sample, $39 \%$ were nonsuppressors; $39 \%$ of both suppressors and nonsuppressors had a severe antecedent life event, and $21 \%$ of suppressors compared to $20 \%$ of non-suppressors had a major difficulty before onset.

Urinary cortisols Using the presence or absence of life events or difficulties as independent variables, their relationship to pre- and post-dexamethasone UFC excretion levels were examined (Table II). Patients with severe life events in the six months before onset had significantly higher 24-hour UFC levels than those without severe life events. Similarly, patients with severe life events in the six months before incorporation into the study had higher 24-hour UFC levels than those without such events. Patients with marked difficulties also had significantly higher 24-hour UFC levels than those without difficulties.

There were no difficulties in 24-hour post-dexamethasone UFC levels in patients with life events or dificulties, compared to those without life events or difficulties. The differences found were not explained by age, as there were no significant differences in age between those with and without life events or difficulties.

TABLE II

24-hour urinary free cortisol (ugm/24 hours) in patients with life events and difficulties (in 65 patients who had pre-dexamethasone UFCs)

\begin{tabular}{|c|c|c|}
\hline & $\begin{array}{c}\text { Severe events } \\
n=28\end{array}$ & $\begin{array}{c}\text { No events } \\
n=37\end{array}$ \\
\hline 6 months before onset & $172.7 \pm 62.3$ & $\begin{array}{l}147.9 \pm 86.9 \\
F=4.3, \text { df } 1,61, P<0.05\end{array}$ \\
\hline \multirow[t]{2}{*}{6 months before test } & $183.0 \pm 68.3$ & $\begin{array}{l}146.1 \pm 80.1 \\
F=4.6, d f 1,63, P<0.05 \neq\end{array}$ \\
\hline & $\begin{array}{c}\text { Marked } \\
\text { difficulties } \\
n=18\end{array}$ & $\begin{array}{c}\text { No } \\
\text { difficulties } \\
n=47\end{array}$ \\
\hline $\begin{array}{l}1 \text { year or greater } \\
\text { before onset }\end{array}$ & $190.4 \pm 57.8$ & $\begin{array}{l}146.4 \pm 81.4 \\
F=10.53, \text { df } 1,55, P<0.005^{*}\end{array}$ \\
\hline
\end{tabular}

- Brown-Forsythe Test (because of unequal variances).

= ANOVA.

\section{Discussion}

The results of the study revealed that over half the patients seen in this hospital-based study had a precipitant-a life event or difficulty. Patients with endogenous depression were equally likely to have a preceding life event as those with neurotic depression. Patients with life events had greater total PSE and HAMD scores than patients without; those with a first onset of depression had a greater likelihood of an antecedent life event than those with previous episodes of depression. Suppressor/non-suppressor status was not associated with a greater or lesser likelihood of an antecedent life event or difficulty, 
but patients with life events or difficulties had greater 24-hour UFC excretion levels than those without.

The results must be considered in the light of possible bias. The use of a largely hospital-based sample implies that patients in the study were likely to be suffering from a severe form of depression; such a sample would be unlikely to be biased in terms of an excess of antecedent life events. It is likely, though, that they may be biased towards fewer life events, as indicated by Miller \& Ingram (1976), who found that the presence of stress made it less likely for someone with psychiatric symptoms to seek help. The rating of life events itself was carried out by trained raters, using an instrument of known reliability. Diagnostic grouping of patients was carried out at the end of the study, using a computer programme. Such a procedure largely rules out possible bias in allocation of patients to diagnostic groupings on the basis of knowledge as to the presence or absence of a precipitant.

The present study replicates previous reports in the literature of the difficulty in distinguishing between endogenous and neurotic depression on the basis of the presence or absence of a precipitant (Leff el al, 1970; Paykel, 1974; Thompson \& Hendrie, 1972; Brown \& Harris, 1978). Although the assumption that the PSE classes, in particular $\mathbf{R}$, corresponded to conventional classifications is open to criticism, the NDI allocation of patients to endogenous neurotic groupings resulted in similar findings.

In addition to clinically derived groupings, we sub-divided patients on the basis of their status on the DST, non-suppression having been shown to be associated with endogenous depression. Nonsuppression on the DST was not associated with a greater or lesser likelihood of antecedent life events.

A surprising finding was that patients with life events had more severe symptomatology as measures on the total PSE and HAMD scores. This difference seems partially explicable in terms of the greater scores of patients with life events for symptoms such as tension and worrying, which are not specific to the depressive syndrome. These patients also had greater symptom scores for items such as early waking and loss of appetite, which are traditionally seen as endogenous symptoms. Brown el al (1979) found that such symptoms were more likely to be found in those without life events, but this discrepancy may be partly explained by different methods of measuring symptoms. We utilised the PSE, which has three levels for most symptoms (0-72), whereas in Brown's study, symptoms were rated as either present or absent. A more general criticism can be levelled at methods of measurement and conceptualisation of severity. This concept is clearly a multidimensional one, and the summed score on a rating scale cannot be totally satisfactory means of quantifying the severity of an illness.

The finding of a greater likelihood of experiencing an event in patients with a first onset of depression, compared to those with previous episodes, had not-to our knowledge-been previously reported. This finding is open to numerous interpretations. It may indicate that social factors are more important in the onset of depression, but that once a patient has developed such depression, other factors (either psychological or somatic) may assume greater importance. Alternatively, the inclusion of events only if they occurred in the previous six months may have missed associations with more distant events that may be of greater importance in those with recurrent depression.

The emergence of associations between life events or difficulties and alterations in hypothalamicpituitary-adrenal function was an unexpected finding. The finding of increased 24-hour UFC levels in patients with life events and with difficulties raises the question of the role of stress in hypothalamic-pituitary-adrenal function. A stress hypothesis might suggest that in some patients, these changes are adaptive responses to environmental stressors, rather than manifestations of purely internal biological processes. The literature on the relationship of environmental stress and neuroendocrine change, which has been summarised by Mason (1968), would uphold such a hypothesis. However, a limitation of most of this work is that it is confined to animals or to normal humans under controlled laboratory conditions; very few studies have considered the impact of stressful events on cortisol levels in depressed patients. Sachar (1967) reported elevation of urinary cortisols in depressed patients following stressful confrontations during psychotherapy. Traskman et al (1980) using the Homes-Rahe scale, reported that patients with life events had increased CSF cortisol levels. Both these studies, though, have major methodological shortcomings in their measurement of stress, and this criticism can in fact be levelled at most studies that have examined the relationship between stress and depressive illness. The decision to rate the presence of a precipitant is very often the subjective opinion of the investigators, with little attempt to systeematise the ratings, whereas the 
present study utilised a standardised instrument of known reliability, with well defined rules for rating of events.

The findings reported here cast further doubt upon the value of the endogenous/neurotic division of depression. A central tenet of the endogenous concept-the absence of a precipitant-has not been upheld by this or many other studies. Another facet of the term is its implication of disease processes arising within the organism, independently of external circumstances. As Heron
(1965) has pointed out, this implies a rigid separation of the environmental and the biological, which has little empirical justification. The relationship of life events and difficulties to endocrine changes in this study suggests an interaction between the environmental and biological domains.

\section{Acknowledgements}

We should like to thank the following people who have cont ributed in various ways to the study: Professor G. W. Brown. Ms T. Harris, Dr T. Craig, Dr A. H. Mann, the Caversham Health Centre, the staff of Nicol Ward and the patients who took part.

\section{References}

BEBBINCiTON, F. E., TENNANT, C. \& HURRY, J. (1981) Adversity and the nature of psychiatric disorder in the community. Jourmal o!! Affective Disorders, 3, 345-366.

BROWN, G. W. \& HARRIS, T. (1978) Social Origins of Depression. London: Tavistock.

BROWN, M. B. \& FORSYTHE, A. B. (1974) The small sample behaviour of some statistics which test the equality of several means. Techmometrics.. 16, 129-132.

- - NI BROI.CHAIN, M. \& HARRIS, R. D. (1979) Psychotic and neurotic depression: aetiological and background factors. Journal of Affective Disorder, 1, 195-211.

Cai.loway, S. P., Dolan, R. J., FonaciY, P., De SOUZA, F. V. A. \& Wakel.INC, A. (1984) Endocrine changes and clinical profiles in depression: I. The dexamethasone suppression test. Psychological Medicine, 14, 749-758.

CARNEY, M. W. P., ROTH, M. \& GARSIDE, R. F. (1965) The diagnosis of depressive syndromes and the prediction of E(T response. British Journal of Psychiatry, 111, 659-674.

CARROLL, B. J. (1982) The dexamethasone suppression test for melancholia. British Journal of Psvchiatrv, 140, $292-304$.

- CURTIS, G. C. \& MENDELS, C. (1976) Neuroendocrine regulation in depression. Archives of General Psvchiarry, $33,1051-1057$.

HAMILTON, M. (1960) A rating scale for depression. Journal of Neurologv. Neurosurgery and Psychiatry, 23, 56-62.

HERON, M. J. (1965) A note on the concept endogenous-exogenous. British Journal of Medical Psychologv, 38, $241-245$.

HOI.DEN, N. L. (1983) Depression and the Newcastle scale: their relationship to the dexamethasone suppression test. British Journal of Psychiatry, 142, 505-507.

LEFF, M. J., ROATCH, J. F. \& BUNNEY, W. E. (1970) Environmental factors preceding the onset of severe depression. Psychiatry, 33, 293-311.

LLOYD, C. (1980) Life events and depressive disorder reviewed: II. Events as precipitating factors. Archives of Generul Psychiutrv, 37. $541-548$.

MASON, J. W. (1968) A review of psychoendocrine research on the pituitary-adrenal-cortical system. Psychosomatic Medicine, 30, Suppl. 576-607.

MIL.LER, P. A. \& INGHAM, J. (1976) Friends, confidants and symptoms. Social Psychialry, 11, 51-58.

PAYKEL, E. S. (1974) Recent life events and clinical depression. In Life Siress and IIIness (eds. E. K. E. Gunderson and R. H. Rahe). Springfield, Illinois: Thomas.

SACHAR, E. J. (1967) Corticosteroids in depressive illness. A longitudinal psychoendocrine study. Archives of Generul Psvichialry, 17. 554-567.

SPITZER, R. L., ENDICOTT \& ROBINS, E. (1978) Research diagnostic criteria: rationality and reliability. Archives of General Psychiatrv. 35, 773-782.

THOMPSON, K. C. \& HENDRIE, H. C. (1972) Environmental stress in primary depressive illness. Archives of General Psychiatry, 26. $130-132$.

Traskman, L., TYBinG, G., ASBerG, M., BertilsSen, L., LANTO, O. \& SCHAl.I.ING, D. (1980) Cortisol in the (SF of depressed and suicidal patients. Archives of General Psychiatry, 37, 761-767.

WING, J. D., COOPER, J. E. \& SARTORIUS, N. (1974) The Measurement and Classification of Psychiatric Sylmptoms. London: Cambridge University Press.

*R. J. Dolan, MRCPsych, Formerly: Wellcome Research Fellow. Currently: Senior Registrar, The Maudsley Hospital, Denmark Hill, London SE5 $8 A Z$

S. P. Galloway, MD, MRCPsych, MRCP, Formerly: Wellcome Research Fellow, Consultant Psychiatrist, Fulbourne Hospital, Cambridge

P. Fonagy, PHD, DipPsych, Honorary Lecturer in Psychology

F. V. A. De Souza, BSc, Principal Biochemist

A. Wakeling, PhD, FRCPsych, Professor of Psychiatry

Academic Department of Psychiatry, The Royal Free Hospital, Pond Street, London NW3 2QG

*Correspondence

(Accepled 16 November 1984) 